\title{
Proteomic and metabolomic responses to connexin43 silencing in primary hepatocyte cultures
}

Citation for published version (APA):

Vinken, M., Maes, M., Cavill, R., Valkenborg, D., Ellis, J. K., Decrock, E., Leybaert, L., Staes, A., Gevaert, K., Oliveira, A. G., Menezes, G. B., Cogliati, B., Zaidan Dagli, M. L., Ebbels, T. M. D., Witters, E., Keun, H. C., Vanhaecke, T., \& Rogiers, V. (2013). Proteomic and metabolomic responses to connexin43 silencing in primary hepatocyte cultures. Archives of Toxicology, 87(5), 883-894. https://doi.org/10.1007/s00204012-0994-0

Document status and date:

Published: 01/05/2013

DOI:

10.1007/s00204-012-0994-0

Document Version:

Publisher's PDF, also known as Version of record

Document license:

Taverne

Please check the document version of this publication:

- A submitted manuscript is the version of the article upon submission and before peer-review. There can be important differences between the submitted version and the official published version of record.

People interested in the research are advised to contact the author for the final version of the publication, or visit the DOI to the publisher's website.

- The final author version and the galley proof are versions of the publication after peer review.

- The final published version features the final layout of the paper including the volume, issue and page numbers.

Link to publication

\footnotetext{
General rights rights.

- You may freely distribute the URL identifying the publication in the public portal. please follow below link for the End User Agreement:

www.umlib.nl/taverne-license

Take down policy

If you believe that this document breaches copyright please contact us at:

repository@maastrichtuniversity.nl

providing details and we will investigate your claim.
}

Copyright and moral rights for the publications made accessible in the public portal are retained by the authors and/or other copyright owners and it is a condition of accessing publications that users recognise and abide by the legal requirements associated with these

- Users may download and print one copy of any publication from the public portal for the purpose of private study or research.

- You may not further distribute the material or use it for any profit-making activity or commercial gain

If the publication is distributed under the terms of Article $25 \mathrm{fa}$ of the Dutch Copyright Act, indicated by the "Taverne" license above, 


\title{
Proteomic and metabolomic responses to connexin 43 silencing in primary hepatocyte cultures
}

\author{
Mathieu Vinken $\cdot$ Michaël Maes $\cdot$ Rachel Cavill $\cdot$ Dirk Valkenborg $\cdot$ James K. Ellis • \\ Elke Decrock · Luc Leybaert • An Staes · Kris Gevaert • André G. Oliveira • Gustavo B. Menezes • \\ Bruno Cogliati · Maria Lúcia Zaidan Dagli · Timothy M. D. Ebbels · Erwin Witters • \\ Hector C. Keun · Tamara Vanhaecke • Vera Rogiers
}

Received: 10 July 2012/Accepted: 27 November 2012/Published online: 7 December 2012

(c) Springer-Verlag Berlin Heidelberg 2012

\begin{abstract}
Freshly established cultures of primary hepatocytes progressively adopt a foetal-like phenotype and display increased production of connexin 43 . The latter is a multifaceted cellular entity with variable subcellular locations, including the mitochondrial compartment. Cx43 forms hemichannels and gap junctions that are involved in a
\end{abstract}

Electronic supplementary material The online version of this article (doi:10.1007/s00204-012-0994-0) contains supplementary material, which is available to authorized users.

M. Vinken $(\bowtie) \cdot$ M. Maes $\cdot$ T. Vanhaecke $\cdot$ V. Rogiers

Department of Toxicology, Faculty of Medicine and

Pharmacy, Center for Pharmaceutical Research,

Vrije Universiteit Brussel, Laarbeeklaan 103,

1090 Brussel, Belgium

e-mail: mvinken@vub.ac.be

R. Cavill - J. K. Ellis - T. M. D. Ebbels - H. C. Keun Biomolecular Medicine, Department of Surgery and Cancer, Faculty of Medicine, Imperial College London, Sir Alexander Fleming Building, South Kensington, London SW7 2AZ, UK

Present Address:

R. Cavill

Department of Toxicogenomics, Maastricht University,

PO Box 616, 6200 MD Maastricht, The Netherlands

D. Valkenborg · E. Witters

Vlaamse Instelling voor Technologisch Onderzoek,

Boeretang 200, 2400 Mol, Belgium

D. Valkenborg · E. Witters

Department of Biology and Center for Proteomics, Universiteit

Antwerpen, Groenenborgerlaan 171, 2020 Antwerpen, Belgium

D. Valkenborg

Interuniversity Institute for Biostatistics and Statistical

Bioinformatics, Hasselt University, Agoralaan 1,

3590 Diepenbeek, Belgium plethora of physiological and pathological processes, such as apoptosis. The present study was conducted with the goal of shedding more light onto the role of connexin 43 in primary hepatocyte cultures. Connexin 43 expression was suppressed by means of RNA interference technology, and the overall outcome of this treatment on the hepatocellular proteome and metabolome was investigated using tandem mass tag-based differential protein profiling and ${ }^{1} \mathrm{H}$ NMR spectroscopy, respectively. Global protein profiling revealed a number of targets of the connexin 43 knock-down

E. Decrock · L. Leybaert

Department of Basic Medical Sciences, Physiology Group, Faculty of Medicine and Health Sciences, Universiteit Gent, De Pintelaan 185, 9000 Ghent, Belgium

\section{A. Staes $\cdot$ K. Gevaert}

Department of Medical Protein Research,

Vlaams Instituut voor Biotechnologie,

Albert Baertsoenkaai 3, 9000 Ghent, Belgium

\section{A. Staes - K. Gevaert}

Department of Biochemistry, Faculty of Medicine and Health Sciences, Universiteit Gent, Albert Baertsoenkaai 3, 9000 Ghent, Belgium

\section{A. G. Oliveira · G. B. Menezes}

Department of Morphology, Institute of Biological Sciences, Universidade Federal de Minas Gerais, Belo Horizonte, Brazil

B. Cogliati · M. L. Z. Dagli

Department of Pathology, School of Veterinary Medicine and Animal Science, University of Sao Paulo,

São Paulo, Brazil 
procedure, including mitochondrial proteins (heat shock protein 60 , glucose-regulated protein 75 , thiosulphate sulphurtransferase and adenosine triphosphate synthase) and detoxifying enzymes (glutathione S-transferase $\mu 2$ and cytochrome P450 2C70). At the metabolomic level, connexin43 silencing caused no overt changes, though there was some evidence for a subtle increase in intracellular glycine quantities. Collectively, these data could further substantiate the established existence of a mitochondrial connexin pool and could be reconciled with the previously reported involvement of connexin 43 signalling in spontaneously occurring apoptosis in primary hepatocyte cultures.

Keywords Primary hepatocyte $\cdot$ Connexin 43 .

Proteomics · Metabolomics

\begin{tabular}{|c|c|}
\hline Abbreviatio & \\
\hline ATP & Adenosine triphosphate \\
\hline $\mathrm{Cx}$ & Connexin \\
\hline DDA & Data-dependent acquisition \\
\hline GAPDH & $\begin{array}{l}\text { Glyceraldehyde-3-phosphate } \\
\text { dehydrogenase }\end{array}$ \\
\hline GO & Gene ontology \\
\hline GRP75 & Glucose-regulated protein 75 \\
\hline HSP60 & Heat shock protein 60 \\
\hline IPI & International protein index \\
\hline LC/MS & Liquid chromatography/mass spectrometry \\
\hline LOWESS & Locally weighted scatterplot smoothing \\
\hline LTQ & Linear ion trap \\
\hline NMR & Nuclear magnetic resonance \\
\hline OT & Orbitrap \\
\hline PbAE2 & $\begin{array}{l}\text { 1,6-Hexanediol diacrylate-based poly-beta- } \\
\text { aminoester }\end{array}$ \\
\hline PBS & Phosphate-buffered saline solution \\
\hline RF & Relative frequence \\
\hline SDS-PAGE & $\begin{array}{l}\text { Sodium dodecyl sulphate polyacrylamide } \\
\text { gel electrophoresis }\end{array}$ \\
\hline siRNA & Small interfering RNA \\
\hline TBS & Tris-buffered saline solution \\
\hline TMT & Tandem mass tags \\
\hline TSP & Trimethylsilyltetradeuteropropionic acid \\
\hline
\end{tabular}

\section{Introduction}

Connexin $(\mathrm{Cx})$ proteins and their channels constitute three levels of cellular communication. First, connexins assemble into hexameric structures, called hemichannels, which dock in pairs at the cell plasma membrane surface to generate gap junctions between neighbouring cells. Gap junctional intercellular communication implies the passive diffusion of small and hydrophilic substances, including glucose, glutamate, glutathione, adenosine triphosphate (ATP), cyclic adenosine monophosphate, inositol trisphosphate and ions. Undocked hemichannels create a second platform for communication, by connecting the cytosol with the extracellular environment and by conveying essential metabolites, like ATP, nicotinamide adenine dinucleotide, glutamate, prostaglandins and glutathione. Hemichannels can also reside at atypical subcellular locations, such as in mitochondria, where they are thought to serve as a conduit for ion fluxes. A third level of communication is formed by connexin proteins themselves, which can affect gene expression patterns independently of gap junction or hemichannel functionality (Decrock et al. 2009; Vinken et al. 2006a, 2011a). The interplay between these three cellular signalling routes is not only of major importance for the maintenance of tissue homeostasis, but also fulfils a key function in a variety of pathological events, including cell death, inflammation, oxidative stress and ischaemic insults (Decrock et al. 2009).

Cultures of primary hepatocytes are prominent in vitro models in pharmacotoxicology (Elaut et al. 2006; Hewitt et al. 2007). However, they are prone to dedifferentiation, which is caused, at least in part, through the induction of an inflammatory response during their isolation from the freshly acquired liver tissue and which is followed by the onset of cell death during their subsequent cultivation (Elaut et al. 2006; Vinken et al. 2006b, 2011b). This deteriorative process is associated with a transition in connexin expression. Indeed, in the adult liver, hepatocytes abundantly produce $\mathrm{Cx} 32$, but in culture, they switch to $\mathrm{Cx} 43$ (Vinken et al. 2006b). The biological relevance of induced hepatocellular Cx43 expression in primary hepatocyte cultures, a process also observed in vivo during hepatocarcinogenesis (Vinken et al. 2008), remains obscure. We previously showed that $\mathrm{Cx} 43$ is not involved in the loss of the differentiated phenotype per se (Vinken et al. 2012a), but rather plays a permissive role in spontaneous apoptosis in primary hepatocyte cultures by involving both gap junction and hemichannel activity (Vinken et al. 2012b). In the current study, we investigate whether $\mathrm{Cx} 43$ protein as such can affect hepatocellular protein production and endogenous metabolism in vitro at a global scale. To this end, $\mathrm{Cx} 43$ expression was suppressed in primary hepatocyte cultures through RNA interference technology followed by evaluation of the resulting proteomic and metabolomic profiles.

\section{Materials and methods}

Chemicals and reagents

The 1,6-hexanediol diacrylate-based poly-beta-aminoester (PbAE2) was synthesized as described elsewhere 
(Vandenbroucke et al. 2008). For liquid chromatography (LC)/mass spectrometry (MS) analysis, all solvents and additives were of ultragrade performance LC grade quality (Biosolve, the Netherlands). All other chemicals were commercially available products of analytical grade and were supplied by Sigma (Belgium), unless specified otherwise.

Hepatocyte isolation and cultivation

Procedures for the housing of rats, and isolation and cultivation of hepatocytes were approved by the local ethical committee of the Vrije Universiteit Brussel (Belgium). Male outbred Sprague-Dawley rats (Charles River Laboratories, Belgium) were kept under controlled environmental conditions with free access to food and water. Hepatocytes were isolated using a two-step collagenase method, including purification by serial differential centrifugation, and cell viability was assessed by trypan blue exclusion (Papeleu et al. 2006). Viable ( $\geq 85 \%$ ) hepatocytes were plated at a density of $0.56 \times 10^{5}$ cells $/ \mathrm{cm}^{2}$ in William's medium $\mathrm{E}$ (Invitrogen, Belgium) supplemented with $7 \mathrm{ng} / \mathrm{ml}$ glucagon, $292 \mathrm{mg} / \mathrm{ml}$ L-glutamine, antibiotics (7.33 I.E./ml sodium benzyl penicillin, $50 \mu \mathrm{g} / \mathrm{ml}$ kanamycin monosulphate, $10 \mu \mathrm{g} / \mathrm{ml}$ sodium ampicillin and $50 \mu \mathrm{g} / \mathrm{ml}$ streptomycin sulphate) and $10 \%$ foetal bovine serum. After 4 h, 1 day, 2 days and 3 days, the cell culture medium was removed and replaced by serum-free medium supplemented with $25 \mu \mathrm{g} /$ $\mathrm{ml}$ hydrocortisone sodium hemisuccinate and $0.5 \mu \mathrm{g} / \mathrm{ml}$ insulin ("hepatocyte culture medium"). Samples were taken on day 1 and day 4 of the cultivation period.

\section{Small interfering RNA transfection}

Cx43 expression was suppressed by small interfering RNA (siRNA) treatment with On-target plus smart pool siRNA from Dharmacon (Belgium), which contains four different siRNA duplexes directed against rat gjal (sense strand sequences: siRNA number 1: 5'-CAACAACCUGGCUGC GAAAUU-3'; siRNA number 2: 5'-UGAUUGAAAUGUC GAGUUAUU-3'; siRNA number 3: 5'-CGUGAAGGGAA GAAGCGAUUU-3'; siRNA number 4: 5'-UUACUGAGA UUCUGCGAUAUU-3' ${ }^{\prime}$ ). Preparation of PbAE2/siRNA complexes was carried out as previously described (Vandenbroucke et al. 2008; Vinken et al. 2012a, b). The siRNA transfection was started $20 \mathrm{~h}$ after cell seeding by replacing the initial cell culture medium by hepatocyte culture medium, containing the PbAE2/siRNA complexes (final siRNA concentration $100 \mathrm{nM}$ ). After $5 \mathrm{~h}$, the cell culture medium was removed and replaced by regular hepatocyte culture medium. The hepatocyte culture medium was renewed another two times $(19 \mathrm{~h}$ and $43 \mathrm{~h}$ post-transfection), and sampling was performed $72 \mathrm{~h}$ posttransfection (i.e., at day 4 of the cultivation period).
Experiments with non-targeting siRNA (Dharmacon, Belgium) were performed in parallel.

Proteomics analysis

For the preparation of total protein lysates, hepatocytes were harvested from cell culture plates by scraping and washed twice with cold phosphate-buffered saline solution (PBS). Pelleted cells were lysed by addition of radio-immunoprecipitation lysis buffer (Thermo Fisher Scientific, Germany) complemented with $1 \%$ phosphatase inhibitor (Thermo Fisher Scientific, Germany) and $1 \%$ protease inhibitor (Thermo Fisher Scientific, Germany). Following controlled sonication and cooled $\left(4^{\circ} \mathrm{C}\right)$ centrifugation for $5 \mathrm{~min}$ at $14,000 \times g$, the supernatant was used for protein concentration determination using a BCA Protein Assay kit (Pierce, Belgium). Samples were spiked with $1 \%$ casein- $\beta$ and $1 \%$ Rapigest SF Surfactant (Waters, Belgium), incubated at $100{ }^{\circ} \mathrm{C}$ for $5 \mathrm{~min}$, mixed and chilled at $4{ }^{\circ} \mathrm{C}$. Equal amounts of protein extracts obtained from three biological replicas were pooled. Each pooled sample was subjected to acetonebased protein precipitation followed by in-solution tryptic proteolysis. The resulting digest was prepared for isotopic peptide labelling using tandem mass tag (TMT) kits and reagents (Thermo Fisher Scientific, Germany) according to the manufacturer's protocol. In addition to the three experimental conditions (i.e., Cx43 siRNA, non-targeting siRNA and control), an additional sample was reconstituted from equal amounts of the three experimental conditions and was used for normalization purposes during quantitative data analysis. The final multiplexed sample was reconstituted from equal amounts of each labelled condition and subjected to three replicate LC/MS analyses. Nanoflow LC/MS/MS was performed on a dual binary channel nanoLC Ultra 2D system (Eksigent, United States of America) connected to a linear ion trap (LTQ) Velos Orbitrap (OT) mass spectrometer (Thermo Fisher Electron, Germany), equipped with a Triversa chip-based electrospray source (Advion Biosystems, United States of America) operating at $1.8 \mathrm{kV}$. A volume of $10 \mu \mathrm{L}$, representing a predigest protein load of $1 \mu \mathrm{g}$, was loaded on a C18 precolumn (PepMap 100, $5 \mu \mathrm{m}$ particles, $20 \mathrm{~mm} \times 200 \mu \mathrm{m}$ internal diameter, Dionex, United States of America). After $5 \mathrm{~min}$, the trapping column was switched in line with an analytical C18 column (Acclaim Pepmap 100, $3 \mu \mathrm{m}$ particles, $150 \mathrm{~mm} \times 75 \mu \mathrm{m}$ internal diameter) (Dionex, United States of America). Gradient elution of peptides was accomplished during a 70-min run. Peptide MS spectra were recorded in the OT with a resolution of 60,000 at $\mathrm{m} / \mathrm{z}$ 400. The maximum injection time was set to $500 \mathrm{~ms}$ for both LTQ and OT, and lock mass was enabled with polysiloxane ion at $\mathrm{m} / \mathrm{z} 445.12024$. Up to five co-eluting peptide masses were selected in data-dependent acquisition (DDA) mode for interrogation on tandem MS. Recurrent masses were 
dynamically excluded from DDA selection during $30 \mathrm{~s}$. The set of selected peptides was analysed by two different mass spectral settings to ascertain an optimal information retrieval. First, a low-energy collision- induced dissociation regime in the LTQ analyser was applied to generate reliable and complementary peptide sequence fragmentation data. Secondly, high-collision energy fragmentation regime in the OT analyser was applied in order to establish reliable TMT reporter ions for robust quantification (Kocher et al. 2009). Raw files of the three replicate analyses were processed via the Proteome Discoverer work flow manager version 2.0 (Thermo Fisher Scientific, United States of America). For peptide identification, fragmentation spectra from both analysers were used for database searches against international protein index (IPI) rat (ipi.RAT.v3.87 containing 39,925 dbase entries) (Kersey et al. 2004) using Sequest version 1.0.43 embedded in Proteome Discoverer 2.0. Carbamidomethylation and the modification of the $N$-termini and lysine by the TMT-reactive group were set as fixed modifications, while oxidation was set as variable modification. Peptide mass tolerance was set at $5 \mathrm{ppm}$, and fragment mass tolerance was set to $0.5 \mathrm{Da}$ and 20 millimass units for the LTQ and OT, respectively. Two missed cleavages were allowed. For confident and high-confident peptide identification, a threshold scheme based on the Sequest Xcorr score was used. The thresholds depend on the charge state of the fragmented molecular ion (Supplementary Table S1). This resulted in a final total of 1,790 rat proteins identified. A gene ontology (GO) analysis of the proteins showed that all major cellular components were sampled (data not shown) and indicated that the sampled set of proteins did not suffer from any major sample preparation bias. A comparative GO profile of the identified hepatocyte proteins was compared with the total rat GO profile and indicated significant enrichment or depletion for hepatocyte-specific cellular components, cellular functions and metabolic processes (Supplementary Table S2). The false discovery rate was assessed by a targetdecoy approach using the reversed sequences of IPI rat. By using the threshold scheme, false discovery rate values of 0.0487 and 0.0081 were obtained for the confident and highconfident peptides, respectively. This reporter ion information was extracted from the tandem MS with a mass tolerance of $20 \mathrm{ppm}$. In the case multiple ions were present within the mass tolerance, the most confident peak was selected. Reporter intensities were normalized to remove systematic effects and possible confounders using a locally weighted scatterplot smoothing (LOWESS) normalization (Yang et al. 2002).

\section{Immunoblotting}

For the preparation of total protein lysates, hepatocytes were harvested from cell culture plates by scraping and washed twice with cold PBS. Cells were homogenized in lysis buffer $(50 \mathrm{mM}$ Hepes, $150 \mathrm{mM} \mathrm{NaCl}, 1 \mathrm{mM}$ ethylenediamine tetra-acetic acid, $2.5 \mathrm{mM}$ ethyleneglycol tetra-acetic acid, $0.1 \%$ Tween 20 and $10 \%$ glycerol) supplemented with $0.1 \mathrm{mM}$ phenylmethylsulphonylfluoride, $5 \mathrm{mM}$ dithiothreitol and protease inhibitor cocktail (Roche, Germany). Following sonication for $10 \mathrm{~s}$, samples were left on ice for $1 \mathrm{~h}$. Cell lysates were centrifuged at $13,791 \times g$ for $5 \mathrm{~min}$, and protein concentrations were determined in the supernatants according to the Bradford procedure (Bradford 1976) using a Bio-Rad protein assay kit (Bio-Rad, Germany). Proteins were fractionated on sodium dodecyl sulphate polyacrylamide (SDS-PAGE) and blotted afterwards onto nitrocellulose membranes (Amersham, UK). Blocking of the membranes was performed with $5 \%$ non-fatty milk in Trisbuffered saline solution (TBS; $20 \mathrm{mM}$ Tris, $135 \mathrm{mM}$ $\mathrm{NaCl}$ ) containing $0.1 \%$ Tween 20. Membranes were incubated overnight at $4{ }^{\circ} \mathrm{C}$ with a primary antibody directed against $\mathrm{Cx} 32, \mathrm{Cx} 43$, heat shock protein 60 (HSP60) or glucose-regulated protein 75 (GRP75) (Table 1), followed by incubation for $1 \mathrm{~h}$ at room temperature with appropriate horseradish peroxidase-conjugated secondary antibodies (Dako, Denmark). Excessive antibody was removed by washing the membranes in Tween-supplemented TBS. The proteins were detected by means of an enhanced chemiluminescence Western blotting system (Amersham, United Kingdom). For semiquantification of the results, blots were further incubated with a glyceraldehyde-3-phosphate dehydrogenase (GAPDH) antibody (Abcam, United Kingdom). Blots were scanned, and densitometric analyses were performed by using the Quantity One software (Bio-Rad, Germany). For Cx43, marker signals in the non-targeting siRNA and the Cx43 siRNA conditions were normalized to the corresponding GAPDH signals and were expressed as percentage of the normalized marker signals in the untreated control condition. For HSP60 and GRP75, marker signals in the Cx43 siRNA condition were normalized to the corresponding GAPDH signals and were expressed as percentage of the normalized marker signals in the nontargeting siRNA condition.

Table 1 Primary antibodies used for immunoblot analysis

\begin{tabular}{llllll}
\hline Antigen & Supplier & Reference & Species & Type & Dilution \\
\hline Cx32 & Sigma & C3470 & Rabbit & Polyclonal & $1 / 500$ \\
Cx43 & Sigma & C6219 & Rabbit & Polyclonal & $1 / 4,000$ \\
HSP60 & Santa Cruz & sc13966 & Rabbit & Polyclonal & $1 / 1,000$ \\
GRP75 & Santa Cruz & sc13967 & Rabbit & Polyclonal & $1 / 1,000$ \\
GAPDH & Abcam & ab8245 & Mouse & Monoclonal & $1 / 20,000$ \\
\hline
\end{tabular}




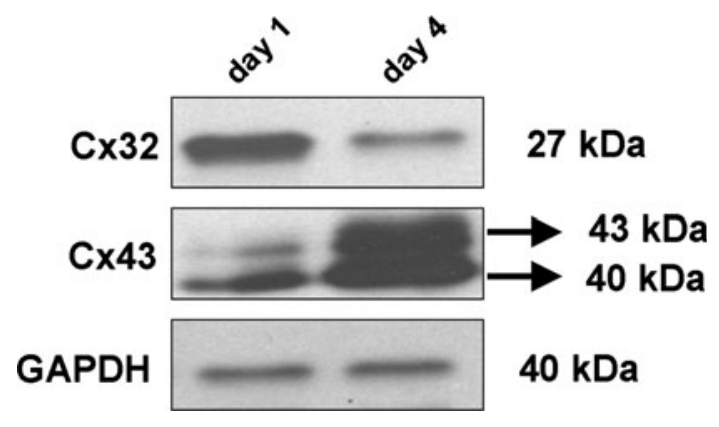

Fig. 1 Connexin expression in primary hepatocyte cultures. Freshly isolated rat hepatocytes were cultivated in a monolayer configuration. Samples were taken on day 1 and day 4 of the cultivation period and subjected to immunoblot analysis as described in the "Materials and methods" section, using primary antibodies that specifically recognize $\mathrm{Cx} 32$ and $\mathrm{Cx} 43$ (Table 1). Blot shown is a representative of three independent experiments

\section{Metabolomics analysis}

Intracellular (i.e., aqueous cell fractions) and extracellular (i.e., cell culture media) samples of the primary rat hepatocyte cultures were prepared as previously described (Ellis et al. 2011). Aqueous soluble metabolites (i.e., intracellular fractions) were isolated from hepatocytes using a chloroform/methanol/water extraction method. After fractionation, the samples were allowed to evaporate at room temperature for about $12 \mathrm{~h}$ to remove any organic solvent, and the remainder was freeze-dried. The lyophilized sample was then reconstituted in $600 \mu \mathrm{L}$ of phosphate buffer and centrifuged for $5 \mathrm{~min}$ at $16,000 \times g$ before being transferred to a standard 5-mm glass nuclear magnetic resonance (NMR) tube. The cell culture media (i.e., extracellular fractions) were prepared for spectroscopic analysis by adding $50 \mu \mathrm{L}$ of $\mathrm{D}_{2} \mathrm{O}$ containing $0.2 \%$ trimethylsilyltetradeuteropropionic acid (TSP) to $550 \mu \mathrm{L}$ of cell culture media sample, of which $550 \mu \mathrm{L}$ was transferred to a standard 5-mm NMR tube. All reagents were checked prior to sample preparation by obtaining $1 \mathrm{D}{ }^{1} \mathrm{H}$ NMR spectra to ensure that they contained no contaminants that could interfere with the downstream spectroscopic analysis. For NMR spectroscopy, high-resolution $1 \mathrm{D}{ }^{1} \mathrm{H}$ NMR spectra of intracellular and extracellular samples were acquired at $14.1 \mathrm{~T}\left(600.13 \mathrm{MHz}{ }^{1} \mathrm{H}\right.$ frequency) using a Bruker Avance 600 spectrometer (Bruker Biospin, Germany) fitted with a 5-mm tube probehead and a Bacs 60 automated sample changer (Bruker BioSpi, Germany). Acquisition of spectra was controlled using Xwin-NMR and Icon-NMR (Bruker Biospin, Germany). Automatic shimming was used to improve the magnetic field homogeneity prior to the acquisition of spectral data for each sample. Carr-Purcell-Meiboom-Gill ${ }^{1} \mathrm{H}$ spectra were obtained using the pulse sequence $\left(\mathrm{RD}-90^{\circ}-\left[\tau-180^{\circ}-\tau\right] \mathrm{n}-\mathrm{AQ}\right)$. The
A
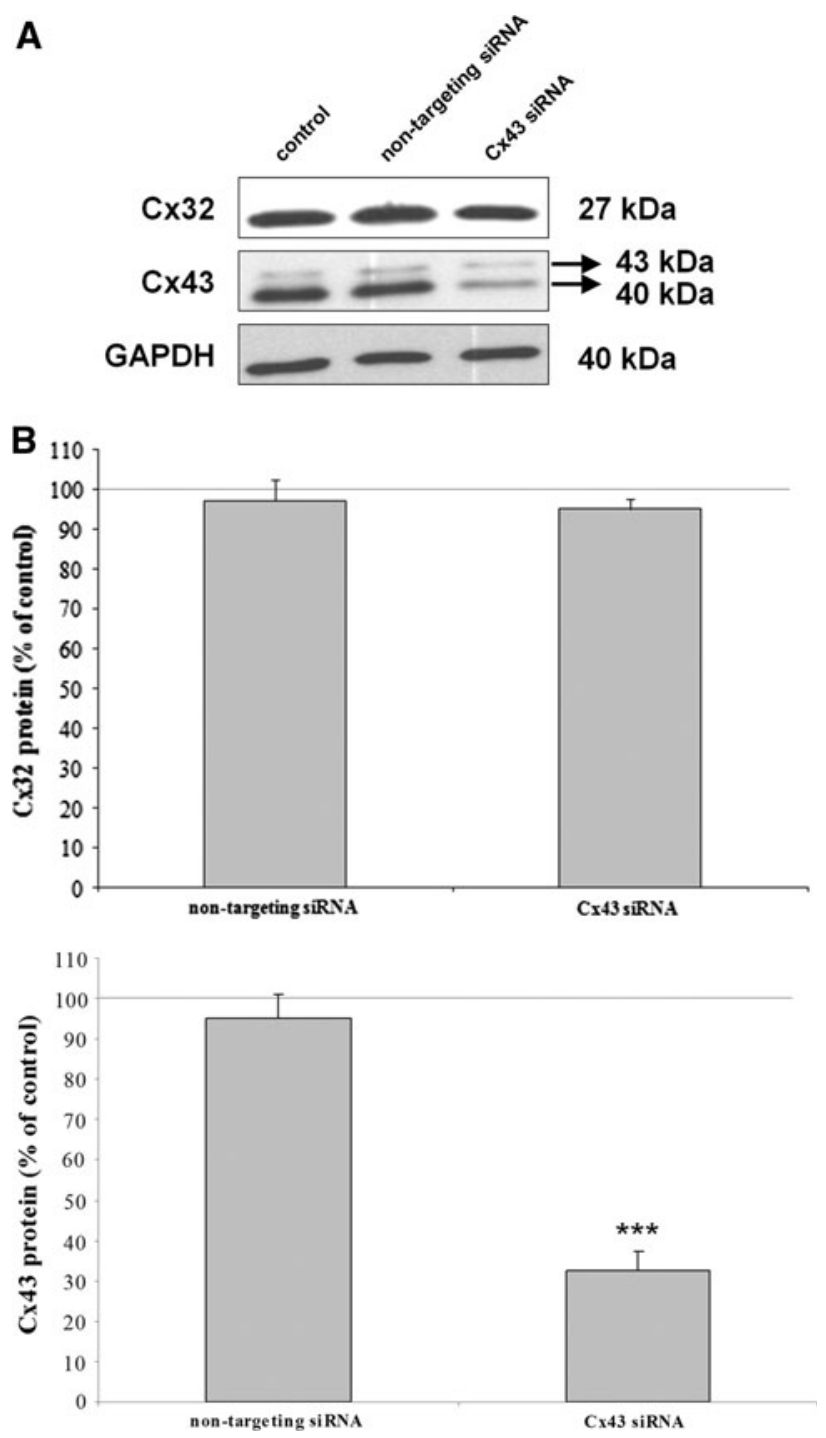

Fig. $2 \mathrm{Cx} 43$ suppression in primary hepatocyte cultures. a Freshly isolated rat hepatocytes were cultivated in a monolayer configuration. Twenty hours after plating, cell cultures were transfected with $100 \mathrm{nM}$ non-targeting siRNA or Cx43 siRNA for $5 \mathrm{~h}$ as described in the "Materials and methods" section. Samples were taken $72 \mathrm{~h}$ posttransfection and subjected to immunoblot analysis as described in the "Materials and methods" section, using a Cx32 or a Cx43 primary antibody (Table 1). b For semi-quantification of the results, Cx32 or Cx43 signals in the non-targeting siRNA and the $\mathrm{Cx} 43$ siRNA conditions were normalized to the GAPDH corresponding signals and were expressed as percentage of the normalized Cx32 (upper panel) or $\mathrm{Cx} 43$ (lower panel) signals, respectively, in the control condition (indicated with a dashed line). Data were expressed as mean $\pm \mathrm{SD}$ of four independent experiments. Results were evaluated by one-way analysis of variance followed by post hoc Bonferroni tests. Asterisks indicate significant differences compared with the non-targeting siRNA condition $(* * * p<0.001)$

fixed echo time $(\tau)$ was set at $400 \mu$ s, with a total spin-echo time of $64 \mathrm{~ms}$. During the acquisition period (AQ, $2.73 \mathrm{~s}$ ), the free induction decay was recorded into $64 \mathrm{k}$ datapoints in the time domain, with a spectral width of $20 \mathrm{ppm}$. 


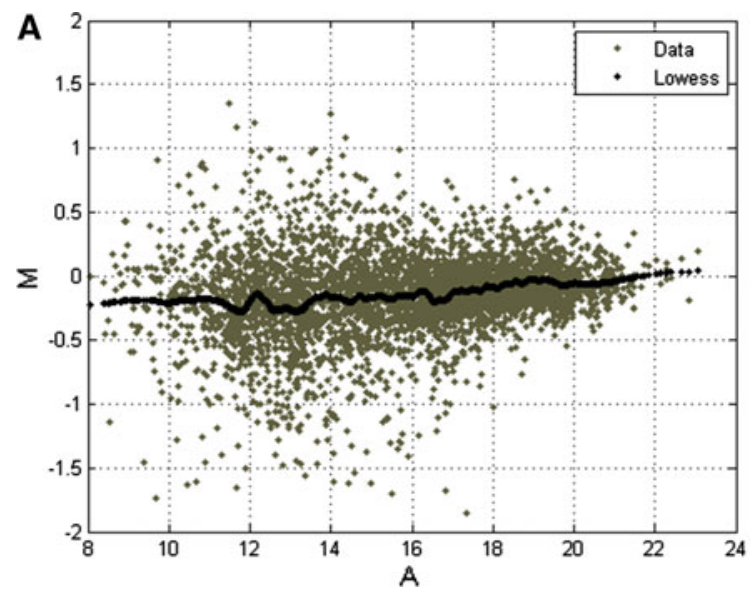

Fig. 3 Effect of $\mathrm{Cx} 43$ suppression on the proteome in primary hepatocyte cultures. Freshly isolated rat hepatocytes were cultivated in a monolayer configuration. Twenty hours after plating, cell cultures were transfected with $100 \mathrm{nM}$ non-targeting siRNA or Cx43 siRNA for $5 \mathrm{~h}$ as described in the "Materials and methods" section. Samples were taken $72 \mathrm{~h}$ post-transfection and subjected to proteomics analysis as described in the "Materials and methods" section.

Typically, spectra were recorded as the sum of 128 transients following 16 dummy scans. In both cases, suppression of the water resonance centred at $\delta \mathrm{H} 4.7 \mathrm{ppm}$ was achieved by the application of a presaturation pulse during the relaxation delay. A line broadening of $0.3 \mathrm{~Hz}$ was applied to each spectrum. Assignment of resonances to specific metabolites was based on the Chenomx profiler in the NMR suite 6.1 software (Chenomx Inc., Canada) and in-house assignment databases. The assignment of intracellular glycine was confirmed by addition of a pure standard at a known concentration to the biological samples.

\section{Statistical analysis}

For immunoblot analyses, data were expressed as mean \pm SD of at least three independent experiments. Results were evaluated by one-way analysis of variance followed by post hoc Bonferroni tests. For the metabolomic analyses, NMR spectral data were imported and processed in Matlab (Mathworks) using in-house software compiled by Dr. T.M.D. Ebbels, Dr. H.C. Keun, Dr. J.T. Pearce and Dr. R. Cavill. ${ }^{1}$ H NMR spectra were automatically phased, baseline corrected, and referenced and normalized to the TSP resonance at $\delta 0$. The spectra were then normalized using a median fold change normalization (Dieterle et al. 2006) before subsequent analysis. In total, 34 metabolites were assigned, and the peak edges of the least overlapped peaks were manually defined for integration. Differences between conditions were assessed using a homoscedastic t-test.

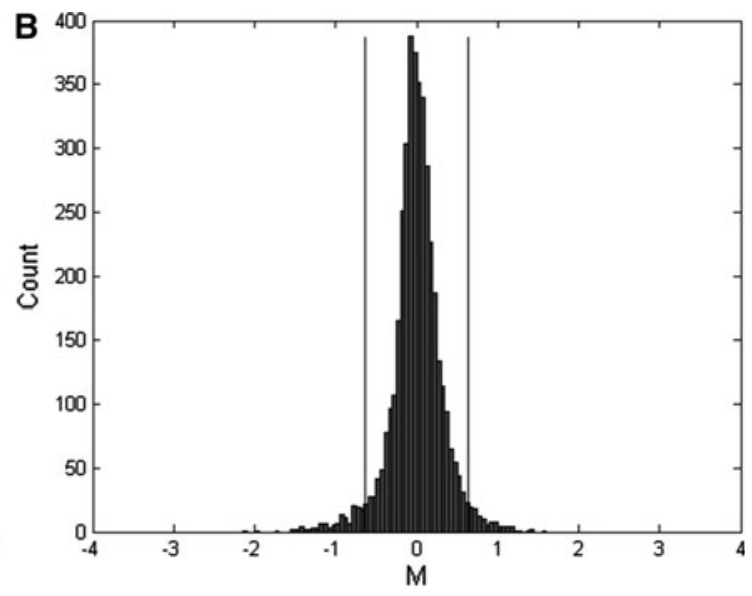

a Data are shown in a MA-plot indicating the $\log 2$ ratio (M) versus average $\log 2$ intensity (A) of the non-normalized reporter intensities of the Cx43 siRNA and non-targeting siRNA conditions. The dots indicate the results of the LOWESS regression. b Data are shown in a histogram of the $\log 2$ ratio after LOWESS normalization. The vertical lines indicate the $95 \% \mathrm{CI}$

\section{Results}

Connexin expression in primary hepatocyte cultures

Hepatocytes mainly harbour $\mathrm{Cx} 32$ in the adult liver (Vinken et al. 2008). However, during isolation and cultivation of primary hepatocytes, Cx32 steady-state protein levels drastically decline, with only marginal Cx32 immunoreactivity at the end of the 4-day cultivation period (Fig. 1). A number of mechanisms could underlie this deterioration of Cx32 production, including oxidative stress, which is triggered during the hepatocyte isolation procedure (Elaut et al. 2006). Simultaneously, $\mathrm{Cx} 43$, a connexin species only expressed by foetal hepatocytes and by adult nonparenchymal cells in vivo (Vinken et al. 2008), becomes gradually detectable. $\mathrm{Cx} 43$ hereby is observed as a dualband signal, representing non-phosphorylated Cx43 (40 kDa; lower band) and phosphorylated Cx43 (43 kDa; upper band), of which the former is predominantly present in primary hepatocyte cultures (Fig. 1). The molecular mechanisms that drive this process are unclear, though a recent study shows that Wnt signalling and hence altered transcriptional regulation could explain $\mathrm{Cx} 43$ appearance in primary hepatocyte cultures (Yamaji et al. 2011).

\section{Cx43 suppression in primary hepatocyte cultures}

RNA interference technology was used to investigate the role of $\mathrm{Cx} 43$ in primary hepatocyte cultures. For this purpose, four siRNA duplexes directed against Cx43 mRNA 
Table 2 Candidate proteins for the validation of the proteomics analysis

\begin{tabular}{|c|c|c|}
\hline $\begin{array}{l}\text { Log2 } \\
\text { ratio }\end{array}$ & Dbase entry & Description \\
\hline \multirow[t]{10}{*}{-1.6} & IPI00197129.1 & Actin, aortic smooth muscle \\
\hline & IPI00189819.1 & Actin, cytoplasmic 1 \\
\hline & IPI00194087.3 & Actin, $\alpha$-cardiac muscle 1 \\
\hline & IPI00896224.1 & Actin, cytoplasmic 2 \\
\hline & IPI00200455.1 & Actin, $\gamma$-enteric smooth muscle \\
\hline & IPI00189813.1 & Actin, $\alpha$-skeletal muscle \\
\hline & IPI00560160.2 & 43-kDa protein \\
\hline & IPI00948496.1 & 33-kDa protein \\
\hline & IPI00958161.1 & Actin, $\gamma$-1 propeptide-like \\
\hline & IPI00960010.1 & $\beta$-actin FE-3 (fragment) \\
\hline-1.5 & IPI00339148.2 & $60-\mathrm{kDa}$ heat shock protein, mitochondria \\
\hline-1.4 & IPI00411230.3 & Glutathione S-transferase $\mu 2$ \\
\hline \multirow[t]{2}{*}{-1.4} & IPI00366293.3 & Thiosulphate sulphurtransferase \\
\hline & IPI00952474.1 & Uncharacterized protein \\
\hline-1.2 & IPI00389571.6 & Keratin, type II cytoskeletal 8 \\
\hline \multirow[t]{3}{*}{-1.0} & IPI00188804.1 & $60 \mathrm{~S}$ acidic ribosomal protein $\mathrm{P} 2$ \\
\hline & IPI00388179.1 & Uncharacterized protein \\
\hline & IPI00734740.2 & Uncharacterized protein \\
\hline 1.0 & IPI00778443.1 & Cytochrome P450 2C70 \\
\hline 1.0 & IPI00551812.1 & ATP synthase subunit- $\beta$, mitochondrial \\
\hline \multirow[t]{5}{*}{1.0} & IPI00231555.1 & $\begin{array}{l}\text { Isoform PYBP1 of polypyrimidine tract- } \\
\text { binding protein } 1\end{array}$ \\
\hline & IPI00390239.1 & $\begin{array}{l}\text { Polypyrimidine tract-binding protein } 1 \\
\text { protein }\end{array}$ \\
\hline & IPI00390801.3 & Uncharacterized protein \\
\hline & IPI00561640.2 & Uncharacterized protein \\
\hline & IPI00562850.2 & 59-kDa protein \\
\hline 1.1 & IPI00206624.1 & 78-kDa glucose-regulated protein \\
\hline 1.4 & IPI00363265.3 & Stress-70 protein, mitochondrial \\
\hline
\end{tabular}

Hepatocyte proteins, identified based on peptide homology, which showed at least a twofold change in relative abundance upon treatment with Cx43 siRNA are considered suitable for further validation. Entries and protein descriptions are obtained from the IPI rat database

were introduced into the hepatocytes by means of $\mathrm{PbAE} 2$, a cationic biodegradable poly-beta-aminoester (Vandenbroucke et al. 2008). Transfections with non-targeting siRNA, bearing at least four mismatches with known rat genes, were performed in parallel in order to check the specificity of the method. Semi-quantitative immunoblot analysis indicated a significant $(p<0.001)$ reduction in $\mathrm{Cx} 43$ protein amounts to $32.5 \pm 4.7 \%$ of the control level in primary hepatocyte cultures exposed to Cx43 siRNA, while $\mathrm{Cx} 43$ levels remained statistically unchanged in non-targeting siRNA-treated cultures. Cx32 levels were unaffected by $\mathrm{Cx} 43$ siRNA, thus showing the specificity of the method (Fig. 2a, b).
Effect of $\mathrm{Cx} 43$ suppression on the proteome in primary hepatocyte cultures

Proteomics analysis was performed on samples taken from primary hepatocyte cultures treated with $\mathrm{Cx} 43$ siRNA or non-targeting siRNA as well as from their untreated counterparts. Figure 3 a displays the result of the normalization on the $\log 2$ of the ratio between the Cx43 siRNAtreated and non-targeting siRNA-treated reporter ions. Scattered points are centred at the zero line, indicating that there is no systematic bias in the quantification channels. Furthermore, the paired abundance measures exhibit a clear drop shape, which suggests that the variability changes with the overall intensity level. From the population of 4,119 tandem MS spectra, $2.5 \%$ upregulated and downregulated peptides were selected. The vertical lines in Fig. $3 \mathrm{~b}$ visualize the $95 \%$ interval of reporter ion ratios between the targeting sample and non-targeting sample. Ratios that fell outside the interval were considered potential candidates for optional investigation by Western blot analysis. Only high-confident peptide identifications were considered for further investigation.

In order to examine the effect of $\mathrm{Cx} 43$ suppression on the overall proteome profile of the cultured hepatocytes, a limited GO profile analysis was performed (Supplementary Table S3). For that purpose, only the identified proteins that were characterized with at least a 1.5 -fold change in relative abundance compared to the control sample were used. It should be noted that peptide ratios were adjusted by median normalization. In addition, the selected proteins have an abundance variability of less than $30 \%$, and the selected proteins were not present in the list of significant altered proteins of the non-targeting siRNA-treated cells. This resulted in a final set of 27 proteins (Supplementary Table S4). In total, 25 proteins were changed in the non-targeting siRNA-treated cells versus the control condition (Supplementary Table S5). From this exercise, it was clear that the most affected cellular compartment upon $\mathrm{Cx} 43$ suppression is the mitochondrion, followed by the cytoplasm and the cellular membrane system. With respect to cellular function and processes, this is reflected in the metal ion-binding protein set, including members of the cytochrome protein family, the actin and actin-binding protein family, chaperones, redox proteins and stress responsive proteins (Supplementary Table S3). A list of 11 candidate proteins for validation of the proteomics analysis was selected thereof (Table 2). A number of these proteins were studied in more detail by means of Western blot analysis (Fig. 4). Since the $\log 2$ ratio data showed that mitochondrial $60-\mathrm{kDa}$ heat shock protein (HSP60) and mitochondrial stress-70 protein/glucose-regulated protein 75 (GRP75) were among the most prominent negative and 

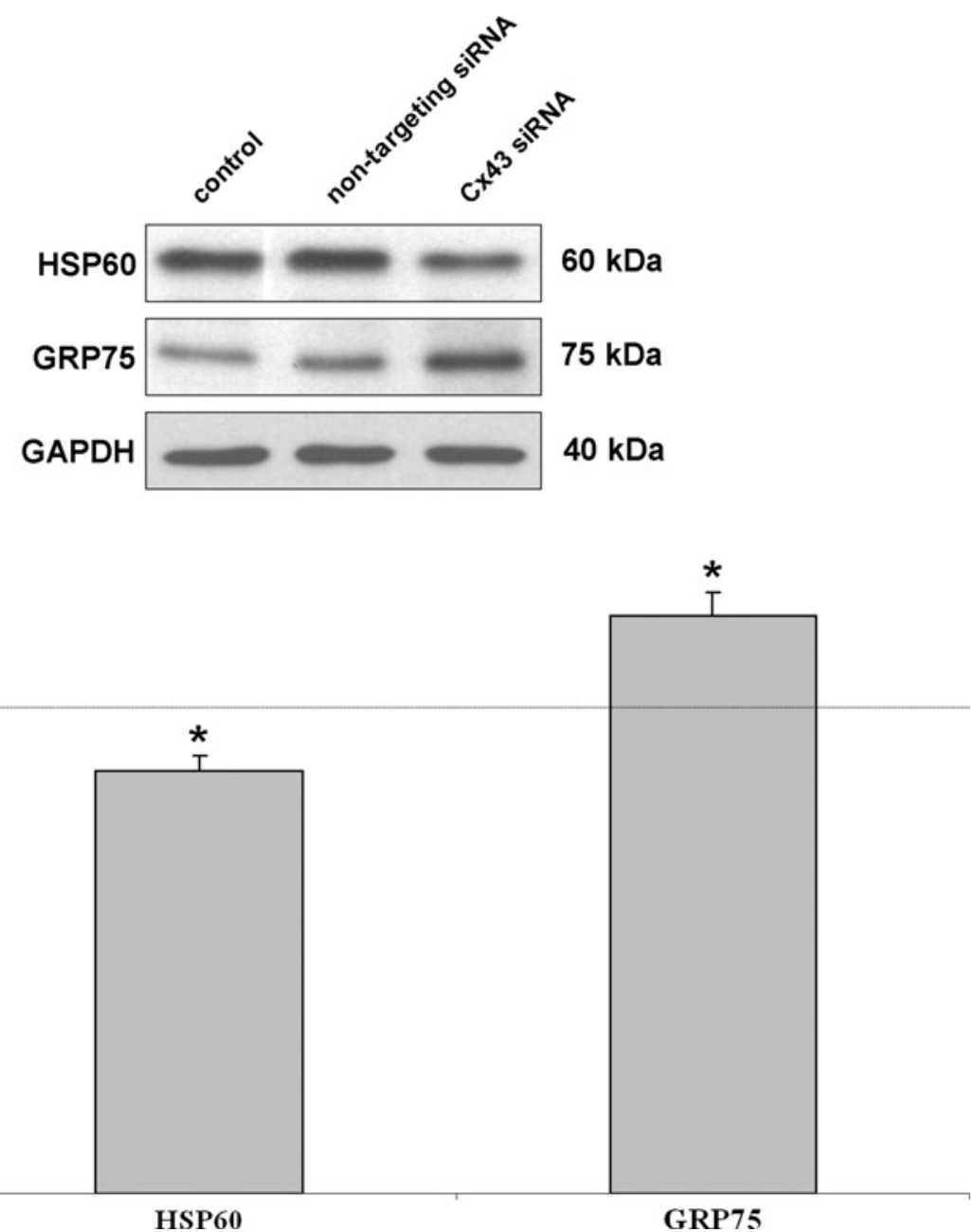

Fig. 4 Validation of the proteomics analysis. Freshly isolated rat hepatocytes were cultivated in a monolayer configuration. Twenty hours after plating, cell cultures were transfected with $100 \mathrm{nM}$ nontargeting siRNA or Cx43 siRNA for $5 \mathrm{~h}$ as described in the "Materials and methods" section. Samples were taken $72 \mathrm{~h}$ posttransfection and subjected to immunoblot analysis as described in the "Materials and methods" section, using primary antibodies directed against HSP60 or GRP75 (Table 1). For semi-quantification of the

positive targets of Cx43 siRNA, respectively, these proteins were selected for further scrutiny. Whole cell lysates were prepared of primary hepatocytes exposed to $\mathrm{Cx} 43$ siRNA and non-targeting siRNA and subjected to SDSPAGE analysis. Following immunoblotting, membranes were incubated with primary antibodies directed against HSP60 and GRP75, and signals were semi-quantified through densitometry and by normalization against GAPDH. By doing so, treatment with $\mathrm{Cx} 43$ siRNA was found to significantly $(p<0.05)$ downregulate hepatocellular HSP60 protein levels to $87.3 \pm 3.2 \%$ of the nontargeting siRNA condition, while GRP75 quantities were raised to $119.0 \pm 4.8 \%$ (Fig. 4). results, marker signals in the $\mathrm{Cx} 43$ siRNA condition were normalized to the corresponding GAPDH signals and were expressed as percentage of the normalized marker signals in the non-targeting siRNA condition (indicated with a dashed line). Data were expressed as mean $\pm \mathrm{SD}$ of seven independent experiments. Results were evaluated by one-way analysis of variance followed by post hoc Bonferroni tests. Asterisks indicate significant differences compared with the non-targeting siRNA condition $\left({ }^{*} p<0.05\right)$
Effect of $\mathrm{Cx} 43$ suppression on the metabolome in primary hepatocyte cultures

Quenching of the $\mathrm{Cx} 43$ production caused no gross changes in the endogenous metabolism of the primary rat hepatocytes at the intracellular or the extracellular level as assessed by NMR-based metabolic profiling. Indeed, the cells appeared to exhibit normal metabolic behaviour in the Cx43 siRNA condition when compared to the control samples, as determined by measuring certain metabolites that represent important metabolic pathways or that are related to changes observed in the proteomics analysis (Table 2). Glucose (i.e., extracellular) and lactate and 


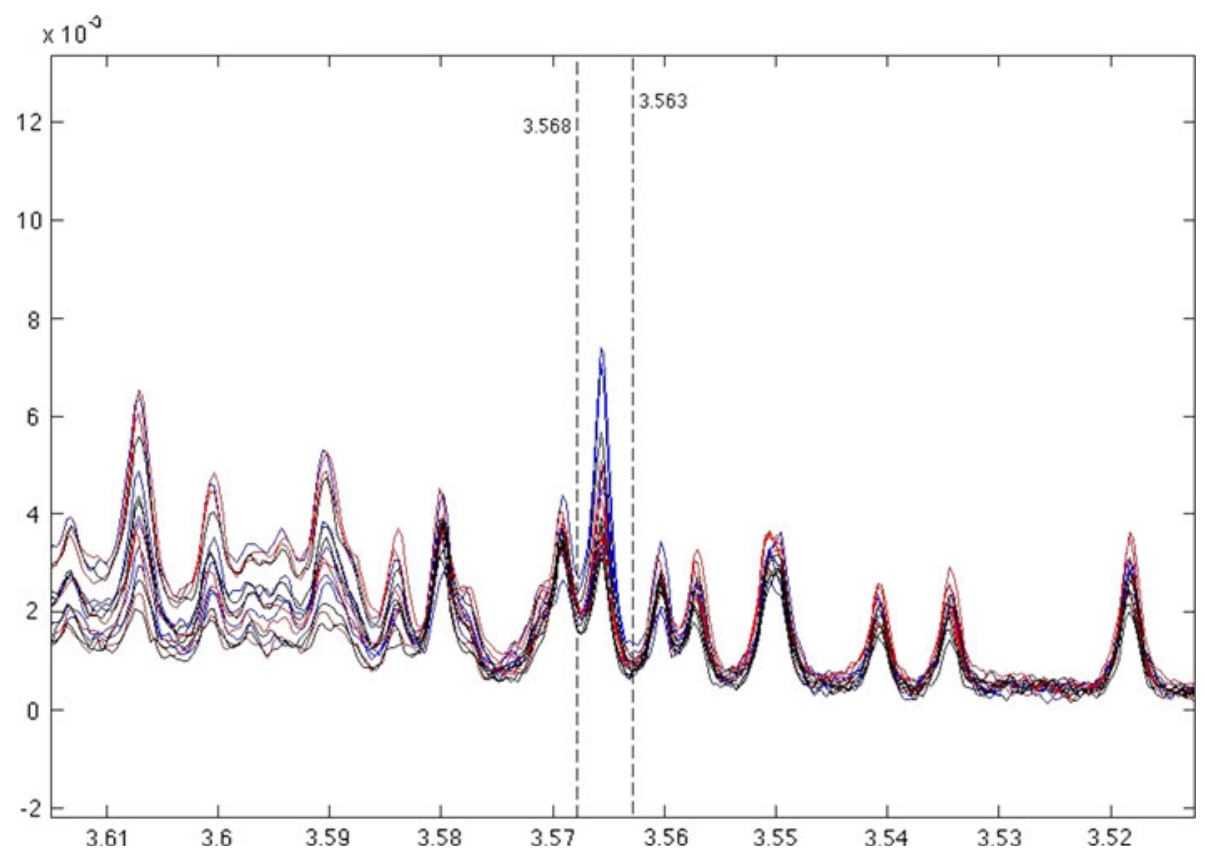

Fig. 5 Effect of $\mathrm{Cx} 43$ suppression on the metabolome in primary hepatocyte cultures. Freshly isolated rat hepatocytes were cultivated in a monolayer configuration. Twenty hours after plating, cell cultures were transfected with $100 \mathrm{nM}$ non-targeting siRNA or Cx43 siRNA for $5 \mathrm{~h}$ as described in the "Materials and methods" section. Samples were taken $72 \mathrm{~h}$ post-transfection and subjected to metabolomics analysis as described in the "Materials and methods" section. Spectra of the intracellular fraction (i.e., aqueous soluble metabolites) are shown. The Cx43 siRNA condition, the non-targeting siRNA condition and untreated control conditions are presented in blue, red and black, respectively. The dotted lines show the area integrated to estimate the levels of glycine (3.563-3.568 ppm) (colour figure online)

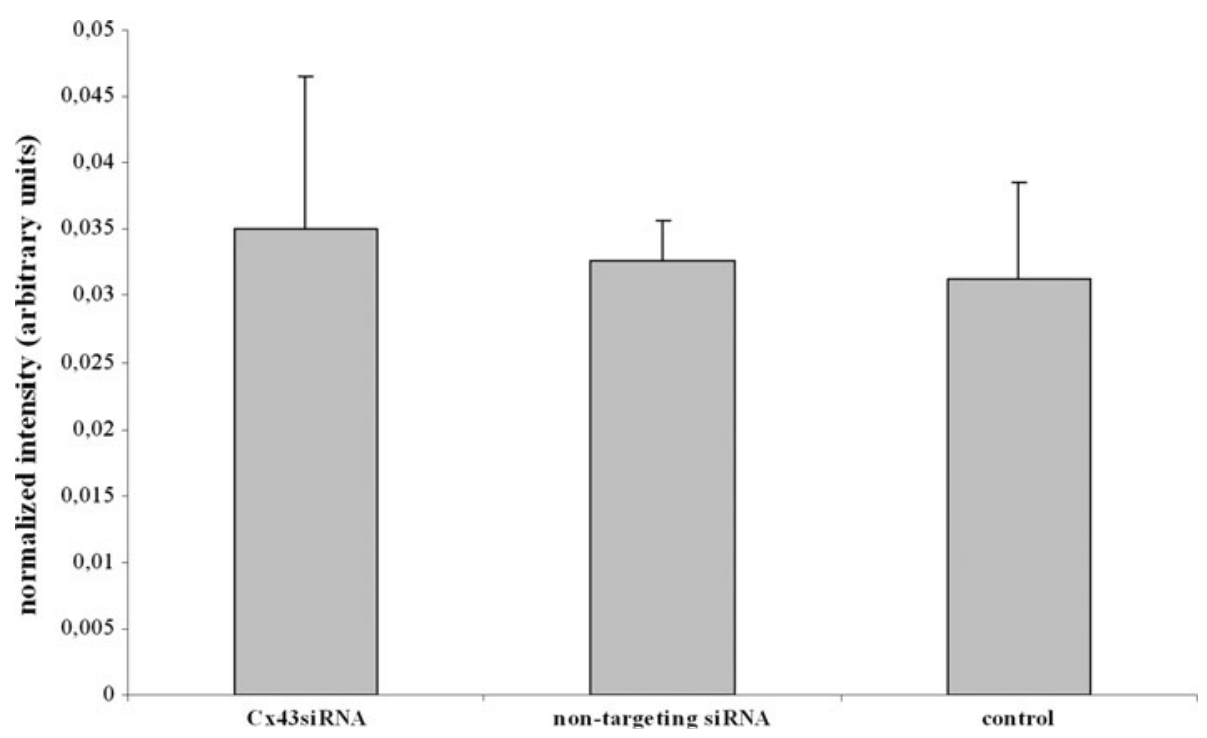

Fig. 6 Effect of $\mathrm{Cx} 43$ suppression on glycine levels in primary hepatocyte cultures. Freshly isolated rat hepatocytes were cultivated in a monolayer configuration. Twenty hours after plating, cell cultures were transfected with $100 \mathrm{nM}$ non-targeting siRNA or Cx43 siRNA for $5 \mathrm{~h}$ as described in the "Materials and methods" section. Samples were taken $72 \mathrm{~h}$ post-transfection and subjected to metabolomics

pyruvate (i.e., extracellular and intracellular) were monitored to investigate possible glycolytic modifications in the Cx43 siRNA condition. No significant changes associated with treatment were observed. Proteomics analysis showed analysis as described in the "Materials and methods" section. Data shown have been normalized using the median fold change method of normalization and represent means per treatment group \pm SD of three independent experiments. Results were evaluated by a means of a homoscedastic t-test

a decrease in glutathione S-transferase levels by $\mathrm{Cx} 43$ siRNA (Table 2), but there was no concomitant alteration in the oxidized and reduced glutathione pool. Visual inspection of the normalized median spectra suggested a 


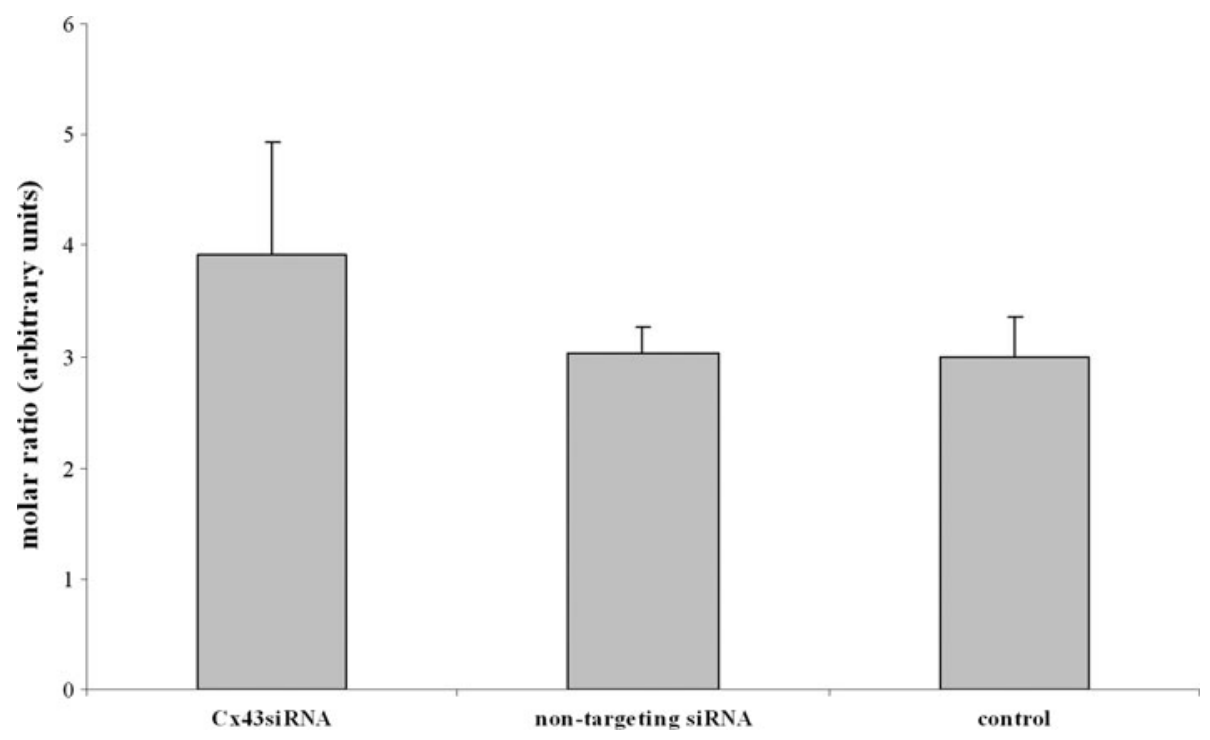

Fig. 7 Effect of $\mathrm{Cx} 43$ suppression on the glycine/pyruvate ratio in primary hepatocyte cultures. Freshly isolated rat hepatocytes were cultivated in a monolayer configuration. Twenty hours after plating, cell cultures were transfected with $100 \mathrm{nM}$ non-targeting siRNA or $\mathrm{Cx} 43$ siRNA for $5 \mathrm{~h}$ as described in the "Materials and methods" section. Samples were taken $72 \mathrm{~h}$ post-transfection and subjected to

subtle increase in glycine levels associated with $\mathrm{Cx} 43$ silencing (Fig. 5). Direct integration of the glycine peak and statistical comparison of the $\mathrm{Cx} 43$ siRNA condition with the non-targeting siRNA and control conditions yielded $\mathrm{p}$ values approaching, but not reaching significance (i.e., 0.067 and 0.066, respectively) (Fig. 6). No significant differences were observed in the ratio between glycine and metabolically linked pyruvate, a strategy that does not rely on normalization (Fig. 7).

\section{Discussion}

Connexins have emerged as multifaceted signalling entities in the last decade, which basically relates to their assembly status and subcellular location. Connexins indeed reside not only at the cell plasma membrane surface, but also at other locations, such as in the nucleus and in mitochondria (Decrock et al. 2009; Vinken et al. 2006a, 2011a). The latter could be supported by the results of the current proteomics study, since a number of mitochondrial proteins were found to be affected by $\mathrm{Cx} 43$ silencing in primary hepatocyte cultures, including HSP60, GRP75, thiosulphate sulphurtransferase and ATP synthase. Yet, the functional relevance of mitochondrial $\mathrm{Cx} 43$ is a matter of debate. It has been postulated that $\mathrm{Cx} 43$ is part of a multiprotein complex that somehow controls mitochondrial homeostasis (Goubaeva et al. 2007). In this regard, mitochondrial Cx43 was recently shown to be required for respiratory complex I activity and hence for ATP metabolomics analysis as described in the "Materials and methods" section. Data shown represent mean glycine/pyruvate ratios per treatment group of three independent experiments. Error bars show 1 standard deviation, and results were evaluated by a means of a homoscedastic t-test

production in cardiomyocytes (Boengler et al. 2012). Mitochondrial $\mathrm{Cx} 43$ could also form hemichannels and may affect potassium ion fluxes, a scenario that equally takes place in cardiomyocytes (Miro-Casas et al. 2009; Rottlaender et al. 2012). This function is reminiscent of apoptosis-regulating Bcl-2 family proteins. In fact, $\mathrm{Cx} 43$ was found to be an apoptosis regulator in a variety of cell types (Decrock et al. 2009; Goubaeva et al. 2007; Klee et al. 2011). Our group recently found that $C_{x} 43$ signalling contributes to the occurrence of spontaneous apoptosis in freshly established cultures of primary hepatocytes, which partially depends on connexin hemichannel functionality (Vinken et al. 2012b). Although the results should be considered with caution and may be speculative, the outcome of the present global protein profiling study could further substantiate this observation. This may equally hold true for the metabolomic screening effort, which indicated a tendency for increased glycine levels upon knock-down of hepatocellular $\mathrm{Cx} 43$. Glycine is known to protect against ischaemia/reperfusion injury (Luntz et al. 2005), an event that is triggered during the isolation of primary hepatocytes from the liver and that negatively affects cell survival (Elaut et al. 2006). The mechanistic basis of the cytoprotective activity of glycine is unknown, but could involve stabilization of the plasma membrane preventing its failure and the onset of necrotic cell death (Kon et al. 2004) or inhibition of calcium signalling (Menger and Vollmar 2007), a cellular process in which connexin-related communication plays a prominent role (Decrock et al. 2011). In the same context, $\mathrm{Cx} 43$ suppression influenced the protein 
levels of two biotransformation enzymes, namely glutathione S-transferase $\mu 2$ and cytochrome P450 2C70. The former is an acknowledged detoxifier of electrophilic compounds, including those generated during oxidative stress (Raza 2011), which occurs in primary hepatocyte cultures as a result of ischaemia/reperfusion insults underwent during the two-step collagenase perfusion isolation procedure (Elaut et al. 2006). The biological meaning of the other protein changes induced by $\mathrm{Cx} 43$ silencing in primary hepatocyte cultures is less clear. In a similar proteomics study, using differential gel electrophoresis, it was found that $\mathrm{Cx} 43$ suppression mainly affects cytoskeletal proteins in primary mouse astrocyte cultures (Olk et al. 2010). Our results are in line with these findings, as both hepatocellular actin and keratin were downregulated by Cx43 siRNA treatment.

In conclusion, the present combined proteomics/metabolomics study revealed a number of cellular targets for Cx43 knock-down in primary hepatocyte cultures. At the same time, these data could be reconciled with the anticipated role of $\mathrm{Cx} 43$ signalling in cell death, in casu spontaneously occurring in primary hepatocyte cultures.

Acknowledgments The authors wish to thank Mr. P. Claes and Mrs. K. Schildermans for their excellent technical assistance. This work was supported by grants from the Research Council of the Vrije Universiteit Brussel-Belgium (OZR-VUB), the Fund for Scientific Research Flanders-Belgium (FWO-Vlaanderen) and the European Union (FP6 project carcinoGENOMICS and FP7/Cosmetics Europe projects HeMiBio and DETECTIVE).

\section{References}

Boengler K, Ruiz-Meana M, Gent S, Ungefug E, Soetkamp D, MiroCasas E, Cabestrero A, Fernandez-Sanz C, Semenzato M, Di Lisa F, Rohrbach S, Garcia-Dorado D, Heusch G, Schulz R (2012) Mitochondrial connexin 43 impacts on respiratory complex I activity and mitochondrial oxygen consumption. J Cell Mol Med 16:1649-1655

Bradford MM (1976) A rapid and sensitive method for the quantitation of microgram quantities of protein utilizing the principle of protein-dye binding. Anal Biochem 72:248-254

Decrock E, Vinken M, De Vuyst E, Krysko DV, D'Herde K, Vanhaecke T, Vandenabeele P, Rogiers V, Leybaert L (2009) Connexin-related signaling in cell death: to live or let die? Cell Death Differ 16:524-536

Decrock E, Vinken M, Bol M, D'Herde K, Rogiers V, Vandenabeele P, Krysko DV, Bultynck G, Leybaert L (2011) Calcium and connexin-based intercellular communication, a deadly catch? Cell Calcium 50:310-321

Dieterle F, Ross A, Schlotterbeck G, Senn H (2006) Probabilistic quotient normalization as robust method to account for dilution of complex biological mixtures: application in ${ }^{1} \mathrm{H}$ NMR metabonomics. Anal Chem 78:4281-4290

Elaut G, Henkens T, Papeleu P, Snykers S, Vinken M, Vanhaecke T, Rogiers V (2006) Molecular mechanisms underlying the dedifferentiation process of isolated hepatocytes and their cultures. Curr Drug Metab 7:629-660
Ellis JK, Athersuch TJ, Cavill R, Radford R, Slattery C, Jennings P, McMorrow T, Ryan MP, Ebbels TM, Keun HC (2011) Metabolic response to low-level toxicant exposure in a novel renal tubule epithelial cell system. Mol BioSyst 7:247-257

Goubaeva F, Mikami M, Giardina S, Ding B, Abe J, Yang J (2007) Cardiac mitochondrial connexin43 regulates apoptosis. Biochem Biophys Res Commun 352:97-103

Hewitt NJ, Lechon MJ, Houston JB, Hallifax D, Brown HS, Maurel P, Kenna JG, Gustavsson L, Lohmann C, Skonberg C, Guillouzo A, Tuschl G, Li AP, LeCluyse E, Groothuis GM, Hengstler JG (2007) Primary hepatocytes: current understanding of the regulation of metabolic enzymes and transporter proteins, and pharmaceutical practice for the use of hepatocytes in metabolism, enzyme induction, transporter, clearance, and hepatotoxicity studies. Drug Metab Rev 39:159-234

Kersey PJ, Duarte J, Williams A, Karavidopoulou Y, Birney E, Apweiler R (2004) The International Protein Index: an integrated database for proteomics experiments. Proteomics 4:1985-1988

Klee P, Allagnat F, Pontes H, Cederroth M, Charollais A, Caille D, Britan A, Haefliger JA, Meda P (2011) Connexins protect mouse pancreatic $\beta$ cells against apoptosis. J Clin Invest 121:4870-4879

Kocher T, Pichler P, Schutzbier M, Stingl C, Kaul A, Teucher N, Hasenfuss G, Penninger JM, Mechtler K (2009) High precision quantitative proteomics using iTRAQ on an LTQ Orbitrap: a new mass spectrometric method combining the benefits of all. J Proteome Res 8:4743-4752

Kon K, Kim JS, Jaeschke H, Lemasters JJ (2004) Mitochondrial permeability transition in acetaminophen-induced necrosis and apoptosis of cultured mouse hepatocytes. Hepatology 40:1170 1179

Luntz SP, Unnebrink K, Seibert-Grafe M, Bunzendahl H, Kraus TW, Buchler MW, Klar E, Schemmer P (2005) HEGPOL: randomized, placebo controlled, multicenter, double-blind clinical trial to investigate hepatoprotective effects of glycine in the postoperative phase of liver transplantation [ISRCTN69350312]. BMC Surg 5:18

Menger MD, Vollmar B (2007) Pathomechanisms of ischemiareperfusion injury as the basis for novel preventive strategies: is it time for the introduction of pleiotropic compounds? Transplant Proc 39:485-488

Miro-Casas E, Ruiz-Meana M, Agullo E, Stahlhofen S, RodríguezSinovas A, Cabestrero A, Jorge I, Torre I, Vazquez J, Boengler K, Schulz R, Heusch G, Garcia-Dorado D (2009) Connexin43 in cardiomyocyte mitochondria contributes to mitochondrial potassium uptake. Cardiovasc Res 83:747-756

Olk S, Turchinovich A, Grzendowski M, Stuhler K, Meyer HE, Zoidl G, Dermietzel R (2010) Proteomic analysis of astroglial connexin43 silencing uncovers a cytoskeletal platform involved in process formation and migration. Glia 58:494-505

Papeleu P, Vanhaecke T, Henkens T, Elaut G, Vinken M, Snykers S, Rogiers V (2006) Isolation of rat hepatocytes. Methods Mol Biol 320:229-237

Raza H (2011) Dual localization of glutathione S-transferase in the cytosol and mitochondria: implications in oxidative stress, toxicity and disease. FEBS J 278:4243-4251

Rottlaender D, Boengler K, Wolny M, Schwaiger A, Motloch LJ, Ovize M, Schulz R, Heusch G, Hoppe UC (2012) Glycogen synthase kinase $3 \beta$ transfers cytoprotective signaling through connexin 43 onto mitochondrial ATP-sensitive $\mathrm{K}^{+}$channels. Proc Natl Acad Sci USA 109:E242-E251

Vandenbroucke RE, De Geest BG, Bonne S, Vinken M, Vanhaecke T, Heimberg H, Wagner E, Rogiers V, De Smedt SC, Demeester J, Sanders NN (2008) Prolonged gene silencing in hepatoma cells and primary hepatocytes after small interfering RNA delivery with biodegradable poly(beta-amino esters). J Gene Med 10:783-794 
Vinken M, Vanhaecke T, Papeleu P, Snykers S, Henkens T, Rogiers V (2006a) Connexins and their channels in cell growth and cell death. Cell Signal 18:592-600

Vinken M, Papeleu P, Snykers S, De Rop E, Henkens T, Chipman JK, Rogiers V, Vanhaecke T (2006b) Involvement of cell junctions in hepatocyte culture functionality. Crit Rev Toxicol 36:299-318

Vinken M, Henkens T, De Rop E, Fraczek J, Vanhaecke T, Rogiers V (2008) Biology and pathobiology of gap junctional channels in hepatocytes. Hepatology 47:1077-1088

Vinken M, Decrock E, De Vuyst E, Ponsaerts R, D'hondt C, Bultynck G, Ceelen L, Vanhaecke T, Leybaert L, Rogiers V (2011a) Connexins: sensors and regulators of cell cycling. Biochim Biophys Acta 1815:13-25

Vinken M, Decrock E, Doktorova T, Ramboer E, De Vuyst E, Vanhaecke T, Leybaert L, Rogiers V (2011b) Characterization of spontaneous cell death in monolayer cultures of primary hepatocytes. Arch Toxicol 85:1589-1596
Vinken M, Buyl K, Vanhaecke T, Rogiers V (2012a) Effects of RNA interference-mediated suppression of connexin 43 production on the expression of differentiation markers in cultures of adult primary rat hepatocytes. ALTEX Proc 1:155-164

Vinken M, Decrock E, Vanhaecke T, Leybaert L, Rogiers V (2012b) Connexin43 signaling contributes to spontaneous apoptosis in cultures of primary hepatocytes. Toxicol Sci 125:175-186

Yamaji S, Droggiti A, Lu SC, Martinez-Chantar ML, Warner A, Varela-Rey M (2011) $S$-adenosylmethionine regulates connexins subtypes expressed by hepatocytes. Eur J Cell Biol 90:312-322

Yang YH, Dudoit S, Luu P, Lin DM, Peng V, Ngai J, Speed TP (2002) Normalization for cDNA microarray data: a robust composite method addressing single and multiple slide systematic variation. Nucleic Acids Res 30:e15 